\title{
Science and Modern Civilization*
}

\author{
By Torataro Shimomura \\ Tokyo University of Education
}

No one would regard philosophers as equipped with broader knowledge than ordinary men, not to mention scientists, are. Socrates is well known for his acknowledgement of his own ignorance, and ever since it has been the tradition of philosophy to be modest and humble. Here, I myself have no intention to tell anything more than the other speakers said so far, all I want to do is just to raise some questions as a philosopher.

When philosophers talk about science, they do not intend to make preaches to science, but they dare to question. They only ask if there is something more fundamental than science. This very question is the core of the philosopher's obstinate concern about the "absolute" or "infinity". The job of philosophy is, after all, I think, to ask ultimate questions.

We are here discussing "science and modern civilization". Certainly it is because science is the fundamental factor in modern civilization. Indeed science is the most decisive element in making up the modern civilization. The credit, however, is not due to the science as itself, but to the connection between science and technology. Recently historians noticed that the birth of modern science gave a greater impetus to modern society even than the Renaiscance and Reformation did. The word "scientific revolution" is coined. But that impetus did not come from

* Translated by S. Ohmori. 
the science as pure knowledge, it came from science-plus-technology or science under the form of technology. Now the nature of the relationship between modern science and technology is not same as that which holds between scientific theory and its application. In modern times, science and technology mutually depend on each other, their relation is "vermittelt". In older times it was quite different, and this difference is an essential difference. The ideal type of Greek science was pure mathematics and the Greek word mathematike meant science in general. This shows that, for the Greeks, science was a pure science detached from technology. There is a famous story according to which Archimedes, one of the greatest Greek scientists, hated to be remembered as a technicianinventor. We can see the same feature also in the curriculum of the middle age universities. Physics in modern sense was excluded from it. It was not a subject to be studied in universities. Even in the 17 th century, experimental sciences were not yet university learnings. The official title of Issac Newton was professor of mathematics. Those things are enough to tell that to those days science had no direct connexion with technology and engineers were "craftmen" having nothing to do with science or scientists. It is a historical fact that for the first time a connexion was established in modern times between science and techno$\log y$.

The modern concept of knowledge and also the nature as well as the method of scientific knowledge are formed in accordance with the peculiar character of the mutual dependence between modern science and technology. The aim of modern science is to have cognizance of mechanism and it tries to understand anything as some mechanism. This is the distinguishing mark of modern science, standing out in sharp contrast to ancient science where cognition was a cognition of "idea " or "form".

The same thing holds for modern technology. And due to this peculiarity of modern technology the modern civilization was formed as distinguished from so-called "Kultur". To be sure, any civilization must stand on some kind of technology, but the peculiar character of 
modern technology gives a unique character to the modern civilization. While the technology of older times was directed mainly to animals and plants, modern technology deals predominantly with inanimate world with an aim to controll it. Generally speaking, the basic function of any technology is, in discovering mechanisms, to adapt ourselves to them or make use of them. But the peculiarity of modern technology lies in that it invents ways to reorganize or reconstruct mechanisms, instead of merely adapting to naturally existing mechanisms. The basic character of older technology was to abide by fixed tradition, but the modern technology is characterized by its incessant revision and innovation. The modern technology is a technology of invention or inventor's technology and due to this it has no fixed limitation. There, everything is principally possible.

These features of modern technology are closely connected with the modern thought that man is the center of all things and there is nothing man can not deal with. Therefore, the problem of technology is not just a problem of technology but is intimately related to thought and life of modern mankind. Rather we would say that the former is nothing but an expression of the latter.

Now the idea of progress is also deeply connected with modern science and technology. The idea of "progress" is familiar to us. It is, however, a modern product and older times did not possess such an idea. We should note here that there must have been progress even in old times as a matter of fact but there did not exist the idea of progress. At that time people accepted more commonly the idea of degeneration or fall of civilization. For example, we find the thought of the Golden Age in the beginning of history among Europeans or the idea of the latter days of the Law among Buddhists. Both of them reveal that they did not have belief in progress. The belief in progress belongs only to modern times.

The marked feature of the idea of progress in modern times is that 
it is directly connected with modern science. As a historical fact, the formation of modern science gave birth to the idea of progress. Progress has been most distinctly recognized than anywhere else. Outside of science and technology, we can see certain changes, but a change is not necessarily a progress. Nevertheless the idea of progress was meant not only the progress of science but the progress of the whole civilization. And it was expected that this whole progress will come out only by the progress of science. Here is the basic character of the modern idea of progress. In short, first the progress of science, then by dint of it the progress of the whole civilization is anticipated-this is the characteristic of the modern idea of progress. What underlies this is a rationalism commonly called 18 th century enlightment philosophy. There the belief in progress revealed itself as a Weltanschauung or a philosophy.

This belief in progress, however, was what philosophers hoped for and not what it was. In the course of history, did things go as philosophers hoped? Without doubt, science and technology made progress, far more than expected, with ever increasing speed and scale. But outside of science, especially in those humanistic domains like morals, arts, philosophy or religion there seems to be no progress at all, or if any, they are not obvious. There have been changes in those fields of course, but they are scarcely regarded as progress. Rather we see something we are inclined to regard as a degeneration of civilization, a certain trend of thought which put more value on the material than on the spiritual. We may not be perfectly justified in regarding such a trend a degeneration. But still we cannot deny that rather negative view in this respect is prevailing in modern times. In that view, the progress of science does not guarantee that of civilization, rather it brings the decadence of civilization. Actually we know several thinkers, since 19 th century, who look upon the civilization as something destined to follow a course of "grow up-get matured-decay-death."

More than that the belief in the progress of civilization became dubious, there is some reason in regarding the progress of science-technology 
as a cause of despair, instead of a hope for a general progress as it was once before. This is because as we cannot stop the almost automatic progress of science, and as it possibly brings the decadence of civilization, it seems unavoidably to lead us to despair. This may sound a little exaggerated, but one thing is clear enough. We cannot expect the progress of civilization to be brought by the progress of science only. So a further scrutiny of the notion of progress is recommendable here.

First, what is the reason why progress is possible exclusively in science and technology but not in other fields? Why the all over progress is not possible? I will try to answer these questions.

The progress in science is not, in its nature, a kind of natural growth, but something to be fabricated by men. It is not something to be waited for, but something to be made by men. This comes from the nature of the method of modern science itself. The method of modern science follows the steps like this : First objectify or "verdinglichen" everything, then dissect them into their elements, next construct mechanisms out of those elements, next reorganize those mechanisms, and finally produce a machine with better function than the nature has. And the above process is nothing but that which makes up the progress in modern science. So the progress is tautologically possible in science and technology, but such progress, however, is impossible or difficult where the above procedure is impossible or difficult. For instance, morals, arts or philosophy are difficult of access for the above method because they require fundamentally men to be the source and agent of free acts. Man is, in his essence, subjective individuum, permitting no objectification. That is the very reason why progress by scientific method is difficult in them. Of course, as even they have some factors which admit objectification or mechanization, progress is possible in them, but only to that extent, such progress is not intrinsic to them, to be sure. The typical philosophy of today which relies entirely on such a way of progress is Marxism. But the very fact that Marxism is built on materialism 
can be taken to confirm my point.

After we admit that progress of science does not necessarily bring that of civilization, we want to ask what then it is for. Science itself cannot answer this question, by the following reason. Science itself, or scientist as scientist, is neutral and indifferent to any value, though scientists as human beings are not so. Modern science has developed itself, since Galilei and Newton, as empirical science, as physics without metaphysics. As such, science does not admit anything transcendent and consequently it, on the other hand, has no right to speak on anything which is outside of or transcends it. Cutting off metaphysics, science becomes science, but at the same time it limits itself. Thus science is in no position to give any answer to the question above.

- Though it is true that progress of science does not necessarily bring progress of civilization, still the former may have the luck to help to realize the latter. Science is double-edged, it is good both for progress and decadence of civilization. We should remember this. We must we1come the progress of science, but keeping in mind that it is not the sufficient condition for the progress of civilization. There is a view according to which what matters for the progress of civilization is the well-balanced progress of social science in comparison to that of natural science. However this sort of view is too optimistic. The issue at stake is just how to get the well-balanced progress, and without answering this the view remains an idle dream. What is important, is to realize the extreme difficulty to produce an answer to it.

I repeat that the idea of progress was formed for the first time in modern bourgeois society, it is an idea of bourgeois society. Now bourgeois society is, as Hegel pointed out, a "System der Bedürfnisse". Being an idea of that utilitarian society, the progress is meant a progress to social welfare and security. And this goal is attained to a satisfactory degree by the development of science and technology. But at the same time the same development brought us the present crisis, a danger of the annihilation of mankind. This tells us that with all its good inten- 
tion the progress of science can lead us to a bad just as well as good end. In other words, science is neutral to value regardless of its intention, and again, in short, science has no ideal, no philosophy. Yesterday's speaker talked about the highly developed stage of robbot designing, but I think that a more fundamental problem is what the purpose of such a technological development is, and also what would be brought to us if that purpose could be materialized. These problems, however, are beyond reach of science or technology.

Let us take a familiar example. Nowadays, our average labor hours per day is reduced to 8 hours thanks to the developments of science and technology, without any loss of our huge production. Moreover, in near future, they say, it can be reduced further by half. Then we all would be freed from physical labour and enjoy a large leisure time. However, then, how do we spend this leisure time, and by what do we fill out those, so to speak, empty hours? This is a very important problem. In these days, people, seems to me, are letting their free time just discharge instead of filling it by whatever it may be. I think most of the leisure time is spent in short lived excitements or sensual entertainments, though this may sound a little intolerant. Or people get ennuied. Ennui is now something ordinary people can feel, but before it was a privileged feeling of the nobility. Well, did scientists and engineers put forth their best effort just in producing such bored time?

Science and technology are neutral and the aim of progress is utility. But utility for what? Progress whereunto? Often people forget these questions. They want progress without noticing the need to "beseelen" it. Even if it is noticed, still it is a problem whether the expected goal could be reached by dint of the progress of science and technology. I do not intend to discuss in detail this difficult problem here, I want to say only one or two things.

Indeed, progress of science does not directly bring progress of civilization, but it still may serve as a basis of the latter. For instance, as a result of the progress of science, our world is becoming one world with 
single spatio-temporal framework. It is on the way of standardization. On the one hand, various nations and cultures tend to lose their uniqueness, but on the other hand mutual understanding and intertexture among them become easier. Thus the "mankind" which was no more than an idea before, becomes an actuality. At the same time, however, two nations so far too far to fight each other now can have a war. There is always a possibility of hostility just as well as friendship.

We may conceive various hopes and doubts on the problem of science and civilization. But it is no good to take impeteously an optimistic or pessimistic view on this matter. We are apt to regard our own time as the final stage of history, but actually it is no more than an intermediate step. The future remains open to us. This view itself also may be just another optimism. But even if it is so, it is an optimism deep rooted in our core. To us the present, not to mention the past, is what is given, and we cannot choose it. What we can choose, at least what looks so, are our plans and goals in future, although we cannot know beforehand whether we can make them or not. Nevertheless we decide and act with a firm expectation of progress. This is the idea of progress which lies deep in us, and this is the idea of progress of higher order than the commonly taken one. And this is intimately related to our moral and religeous spirit. The commonly taken idea of progress is, I think, nothing but a transient form of it in a certain historical stage. 